\title{
Pemberdayaan Gender Pada Tokoh Adat untuk Mendukung Peran Perempuan dalam Pembangunan Desa*
}

\author{
Hadriana Marhaeni Munthe** \& Bisru Hafi
}

Departemen Sosiologi, Fakultas Ilmu Sosial dan Politik

Universitas Sumatera Utara, Indonesia

Diterima: Desember 2018; Disetujui: Desember 2018; Dipublish: Desember 2018

** E-mail: hadrianamunthe@yahoo.com

\begin{abstract}
Abstrak
Dalam masyarakat Batak Pakpak yang menganut sistem budaya patriarki menunjukkan bahwa realitas gender berpotensi memunculkan berbagai isu ketimpangan gender yang berpotensi merugikan kehidupan perempuan dalam aspek pendidikan, kesehatan, pembangunan dan politik. Konstruksi budaya patriarki yang tidak ramah pada perempuan dipresentasikan oleh keputusan adat yang cenderung tidak berpihak pada perempuan melalui kekuasaan tokoh-tokoh adat di lembaga adat. Tokoh-tokoh adat yang berkuasa di lembaga adat ini menempatkan laki-laki sebagai penentu keputusan adat yang kerapkali menjadi penentu keteraturan social (social order) masyarakat di desa ini. Mengingat pengaruh kuasa tokoh-tokoh adat yang mayoritas laki-laki menentukan jalannya keteraturan masyarakat termasuk pembangunan desa diperlukan satu strategi sebagai solusi mengantisipasi gap atau ketimpangan gender yang merugikan perempuan. Dalam hal inidiperlukan pengabdian yaitu pemberdayaan gender untuk menumbuhkembangkan pemahaman kesadaran gender dan kesetaraan gender pada tokoh adat. Hal ini mengingat sampai sejauh ini pemberdayaan konsepsi tentang nilai-nilai kesadaran gender serta kesetaraan gender belum menyentuh wilayah tokoh adat yang berkuasa di lembaga adat di desa ini. Diharapkan setelah melakukan pemberdayaan gender melalui pengabdian akan terjadi transformasi gender yaitu perubahan mindset atau carapandang para tokoh adat yang bias gender menjadi sadar gender.
\end{abstract}

Kata Kunci: Kesadaran Gender, Kesetaraan Gender, Tokoh Adat

\begin{abstract}
In the Pakpak Batak community which adheres to a patriarchal culture system shows that gender reality has the potential to bring up various issues of gender inequality that have the potential to harm women's lives in the aspects of education, health, development and politics. The construction of a patriarchal culture that is not friendly to women is presented by traditional decisions which tend to be impartial to women through the authority of traditional leaders in traditional institutions. These traditional leaders in power in traditional institutions place men as traditional decision makers who often determine the social order of the people in this village. Considering the power of influence of traditional leaders whose majority of men determine the course of community order, including village development, a strategy is needed as a solution to anticipate gender gaps or inequalities that harm women. In this case, service is needed, namely gender empowerment to develop understanding of gender awareness and gender equality in traditional leaders. This is because up to now the conceptualization of the values of gender awareness and gender equality has not touched the territory of the traditional leaders in power in the traditional institutions in this village. It is hoped that after carrying out gender empowerment through service there will be a gender transformation, namely a change in mindset or views of traditional leaders who are gender-biased into gender awareness.
\end{abstract}

Keywords: Gender Awareness, Gender Equality, Customary Figures

How to Cite: Munthe. H.M, Hafi. B. (2018). Pemberdayaan Gender Pada Tokoh Adat untuk Mendukung Peran Perempuan dalam Pembangunan Desa. Journal of Education, Humaniora and Social Sciences (JEHSS). 1 (2): 60-65.

*Didanai oleh: Dana non PNBP USU Tahun 2018, Surat Perjanjian Penugasan dalam Rangka Pelaksanaan Program Pengabdian Kepada Masyarakat Skim Mono Tahun No: 172/UN5.2.3.2.1/PPM/2018, tanggal 16 April 2018 


\section{PENDAHULUAN}

Gender dimaknai sebagai konstruksi sosial yang ideal atau yang diharapkan tentang hubungan antara laki-laki dan perempuan dalam konteks masyarakat maupun budaya tertentu. Sesungguhnya gender bukanlah sesuatu yang harus dipersoalkan sepanjang konstruksi sosial ini tidak memunculkan isu sosial yaitu ketidakadilan gender dan juga ketimpangan terutama pada kelompok perempuan. Beberapa isu sosial yang bersumber dari ketidakadilan gender yang secara realitas lebih sering dialami perempuan diantaranya adalah marginalisasi, subordinasi, beban ganda dan kekerasan (Fakih, 2008; Ginting dkk, 2015; Nunuk, 2004; Elpina, 2016; Revida,2006; Nurmila, 2015; Rokhimah, 2015; Saadawi, 2001).

Realitas ketidakadilan gender dan ketimpangan gender yang lebih dominan dialami perempuan setidaknya diperlihatkan oleh kelompok perempuan Pakpak di pedesaan atau lebih tepatnya di desa Pagagan Julu VIII di kecamatan Sumbul. Ketidak adilan gender dan ketimpangan gender yang dialami oleh kelompok perempuan ini secara spesifik bersentuhan dengan struktur sosial yang disebut kelembagaan adat. Hal ini sangat dimungkinkan terjadi karena lembaga adat menjadi sentral sekaligus penentu keteraturan sosial (social order) pada masyarakat Pakpak. Artinya, dalam konteks kelembagaan sosial nilai adat merupakan fundamen atau peletak utama dari nilai-nilai kelembagaan sosial yang lain seperti keluarga, ekonomi, politik dan pendidikan (Berutu, 1998; Munthe, 2017; Pardede, 2010)

Sesuai dengan keberadaan adat yang dipresentasikan melalui lembaga adat sebagai simbolisasi keteraturan sosial masyarakat Pakpak maka konstruksi gender yang diperlihatkan dalam berbagai kelembagaan sosial pada intinya sangat bias pada laki-laki (male dominated). Realitas dari kelembagaan sosial yang terindikasi male dominated sedemikian dinyatakan dalam berbagai isu sosial yang berkecenderungan lebih banyak dialami oleh perempuan. Di antaranya; perempuan sulit mengakses pendidikan dan kesehatan yang setara dengan laki-laki di keluarga. Selain itu perempuan juga mengalami kesulitan mengakses program-program pembangunan maupun pemberdayaan masyarakat yang difasiltiasi oleh lembaga pemerintahan desa. Situasi yang sedemikian sudah cukup mengkhawatirkan karena ini mulai memunculkan dampak yang kurang baik berupa adanya gejala "feminization of poverty" yaitu suatu kondisi atau situasi yang memperlihatkan perempuan sebagai kelompok yang rentan mengalami proses kemiskinan yang bersumber dari persoalan kultural dan juga struktural. Konkritisasi pemiskinan perempuan di desa ini secara faktual diperlihatkan dalam konstruksi perempuan berbeban ganda (double burden). Realitas beban ganda pada perempuan dimaknai bahwa mereka harus bertanggungjawab dalam pekerjaan rumahtangga dan ikut mencari nafkah yaitu biasanya bekerja di ladang (Munthe, 2017; Pardede, 2010; Bangun, 2013)

Realitas sosial beban ganda yang sudah jelas kurang berpihak pada perempuan di desa ini merupakan agenda yang disikapi dengan serius. Salah satu strategi yang dianggap berpeluang menanggulangi ketidakadilan gender pada perempuan yaitu pentingnya mereformasi nilai-nilai adat yang berpotensi membawa kerugian dalam kehidupan perempuan. Untuk itu perlu dilakukan suatu pendekatan mengantisipasi ketidakadilan atau ketimpangan gender melalui kelembagaan adat dalam konteks masyarakat Pakpak di desa ini.

Konkritisasi dari pendekatan yang bertujuan mengantisipasi semakin dalamnya gap ketimpangan sosial pada perempuan melalui kelembagaan sosial masyarakat Pakpak di desa ini yaitu pentingnya dilakukan pemberdayaan gender. Sebagai salah satu langkah strategis mendukung perubahan sebagai solusi ketimpangan gender pada perempuan yaitu perlu sekali melakukan pemberdayaan gender pada tokoh adat yang mayoritas memegang kekuasaan sentral di kelembagaan adalah ketidakadilan gender pada perempuan yaitu pentingnya mereformasi nilai-nilai adat yang berpotensi membawa kerugian dalam kehidupan perempuan. Untuk itu perlu dilakukan suatu pendekatan mengantisipasi ketidakadilan atau ketimpangan gender melalui kelembagaan adat dalam konteks masyarakat Pakpak di desa ini. Sebagai salah satu langkah strategis mendukung perubahan sebagai solusi ketimpangan gender pada perempuan yaitu perlu sekali melakukan pemberdayaan gender pada tokoh adat yang mayoritas adalah lakilaki di desa Pegagan Julu VIII. 


\section{METODE PENELITIAN}

Metode pendekatan yang dilakukan salah satunya fokus group discussion (FGD) terhadap anggota tokoh adat selaku mitra pengabdian ini. Parameter yang digunakan sebagai acuan keberhasilan pengabdian ini adanya perubahan sikap atau perilaku mitra pegabdian yaitu para tokoh adat. Para tokoh adat yang sudah memiliki pengetahuan yang lebih baik tentang nilai-nilai kesetaraan dan kesadaran gender. Lebih jauh lagi parameter atau acuan yang akan digunakan dan dianggap signifikan melihat hasil pengabdian ini yaitu sampai sejauhmana para tokoh adat mampu mengimplementasikan nilai-nilai kesadaran dan kesetaran gender. Hal ini terlihat tatkala mereka melakukan sidang adat dalam rangka menentukan dan mengambil keputusan yang terkait dengan kesejahteraan sosial di kominitas adat yang ada di desa Pegagan Julu VIII, Sumbul. Peserta FGD dalam pengabdian ini adalah para tokoh adat dan kelompok perempuan.

\section{HASIL DAN PEMBAHASAN}

Metode Focus Group Discussion pada prinsipnya untuk mengetahui pemahaman dan pengetahuan awal (emik) tentang gender para tokoh adat desa maupun kelompok perempuan desa Pegagan Julu VIII, Sumbul. Topik-topik maupun materi FGD yang didiskusikan mencakup konsep gender, relasi gender, ketikadilan gender, ketimpangan gender, kesetaraan dan kesadaran gender pada seluruh tokoh adat di lembaga adat di desa Pegagan Julu VIII.

Mengacu pada topik-topik gender yang sudah ditetapkan peserta FGD pada tokoh adat maupun kelompok perempuan, sesungguhnya mereka tidak sepenuhnya paham konsep gender di tengah masyarakatnya. Mereka memberikan tanggapan bahwa istilah gender itu tidak ada di masyarakatnya. Para tokoh adat memberikan pendapat bahwa gender dimaknai sebagai kumpulan dan konstruksi nilai-nilai adat yang memperlakukan perbedaan peran dan kedudukan antara laki-laki dan perempuan yang sudah menjadi pedoman serta kesepakatan budaya Pakpak desa ini.

Lebih jauh lagi dalam proses FGD yang lebih dominan dikuasai oleh para tokoh adat mengemukakan bahwa nilai kepantasan perempuan dan laki-laki sudah jelas dijalankan dalam segala acara atau ritual adat. Para tokoh adat menjelaskan bahwa adat memainkan peran sebagai pengatur kehidupan dan menentukan keberlangsungan hidup masyarakat Pakpak sehingga ketaatan dan kepatuhan pada nilai-nilai adat sangat diutamakan di dalam komunitas ini. Dalam konteks adat, perempuan ditempatkan pada posisi yang marginal dan tersubordinasi oleh kaum laki-laki sebab sistem pembagian kerja dalam kegiatan-kegiatan yang umum dilakukan dalam adat Pakpak didominasi oleh laki-laki. Hal ini terlihat dalam sistem pembagian kerja seksual dalam adat menempatkan laki-laki sebagai pembicara, perencana dan pengatur kegiatan di adat. Sebaliknya perempuan dilarang berbicara sebab tidak dibenarkan oleh aturan adat. Mereka biasanya hanya diposisikan sebagai pendengar dan menerima segala putusan adat untuk dilaksanakan. Intinya perempuan diposisikan sebagai pekerja adat bukan sebagai konseptor atau pemimpin adat. Setidaknya para tokoh adat Pakpak mengakui mereka hanya meneruskan nilainilai atau pengetahuan adatnya sesuai dengan ajaran-ajaran dari pendahulu mereka yaitu leluhur orang Pakpak.

Topik diskusi berikutnya yaitu mediskusikan tentang ketimpangan gender atau ketidaksetaraan gender dalam relasi gender yang terkait dengan konstruksi nilai-nilai adat Pakpak. Dalam diskusi tentang topik ini muncul berbagai reaksi maupun tanggapan yang berbeda dari para tokoh adat. Pada awalnya mereka bingung dengan topik tersebut sehingga fasilitator mengarahkan serta menjelaskan topik tersebut dalam realitas konkrit kehidupan masyarakat. Fasilitator memberikan contoh riil tentang ketimpangan gender dalam hal pendidikan yaitu siapa yang lebih tinggi tingkat pendidikan perempuan atau laki-laki, siapa yang lebih diutamakan bersekolah tinggi di keluarga Pakpak. Berikutnya dalam hal akses kesehatan serta harta warisan dalam masyarakat Pakpak siapa yang lebih diutamakanm.

Setelah diperjelas oleh fasilitator tentang makna diskusi topik ketimpangan gender akhirnya para peserta sudah mengerti dan tanggapan yang sangat mengejutkan diberikan oleh kebanyakan para dewan adat bahwa tidak ada masalah gender di masyarakat mereka. Demikian pula halnya peserta kelompok perempuan secara spontan memberikan tanggapan tak ada masalah kalau laki-laki lebih diutamakan dalam berbagai hal di keluarga atau di masyarakat. 
Tatkala dipertanyakan oleh fasilitator mengapa kelompok perempuan berpendapat demikian kenapa tidak sebaliknya. FGD ini diperdalam kembali oleh fasilitator bahwa sudah jelas ada kebijakan persamaan gender ditetapkan oleh undang-undang yaitu pengarusutamaan gender yang menekankan kedudukan laki-laki dan perempuan adalah setara di negara. Pernyataan fasilitator dijawab kembali oleh perempuan dengan sedikit malu "kami tak paham aturan itu, kami tahu aturan adat yang mengajarkan supaya selalu tunduk, patuh dan harus mengutamakan kepentingan laki-laki, setelah itu kepentingan kami berikutnya".

Pemetaan awal tentang pengetahuan gender serta ketimpangan gender memperlihatkan suatu realitas bahwa masyarakat Pakpak di desa ini tidak terlalu menyoalkan isu-isu gender. Kebanyakan perempuan berpandangan nilai-nilai adat sudah membiasakan adanya perbedaan laki-laki dan perempuan terutama dalam hal mengistimewakan anak laki-laki.

Realitas ini tercermin dari gambaran emik perempuan Pakpak yang mengkonstruksi pemaknaan bahwa perbedaan gender merupakan realitas obyektif yang harus dijalani, wajib diterima dan tidak perlu dipertanyakan apalagi untuk digugat. Perempuan Pakpak terutama dari lapisan miskin mendefinisikan perbedaan laki-laki dan perempuan merupakan realitas hidup yang suka atau tidak suka harus dijalani. Mereka diharuskan untuk terbiasa dan belajar menerima keadaan hidup yang sedemikian. Bahkan mereka juga seakan-akan tidak begitu menyoalkan mengapa anak laki-laki cenderung diistimewakan daripada anak perempuan di keluarganya. Pandangan yang terkonstruksi mengenai kedudukan perempuan sebagai wujud dari "takdir" dan "kodrat hidup" perempuan. Ini merupakan pemahaman emik yang terlekat pada sebagian besar perempuan bahkan mayoritas perempuan miskin di desa ini.

Nilai emik yang terinternalisir pada diri sebagian besar perempuan miskin juga diadopsi dari nilai-nilai budaya yaitu adat yang patriarkis. Mereka secara sadar dan tidak sadar telah menerima nilai adat Batak Pakpak yang mengharuskan seorang perempuan untuk mengutamakan dan mengedepankan kepentingan anak laki-laki baik di keluarga dan di masyarakatnya.

Pemahaman emik yang terlekat pada perempuan miskin semakin diperkuat oleh sosialisasi dan ajaran yang disampaikan oleh orangtua terutama ibu (inang). Para inang mengajarkan anak perempuan harus hormat dan mengabdi kepada saudara laki-lakinya. Sudah umum para ibu yang bermukim di perdesaan ini menasihati anak perempuan mereka agar membiasakan diri memberikan perhatian yang ekstra dan terbaik kepada turangnya atau anak laki-lakinya. Para ibu juga mengingatkan pada setiap anak perempuan sedari usia muda untuk memandang anak laki-laki bukan hanya sekedar saudaranya saja. Anak laki-laki adalah calon pemimpin yang menggantikan peran orangtua di keluarga dan secara adat laki-laki merupakan kula-kula dari anak perempuan. Legalitas adat yang melekat pada kula-kula berupa kekuasaan mereka sebagai pemberi berkat, ridho (pasu-pasu) dalam segala aspek kehidupan perempuan Batak Pakpak. Pasu-pasu laki-laki sangat diharapkan perempuan sepanjang fase hidupnya yaitu mulai lahir sampai mereka berkeluarga. Setidaknya sosialisasi gender yang bias laki-laki diperlihatkan para "inang" seperti yang dituturkan salah satu perempuan peserta FGD. Perempuan ini mengungkapkan ia tak diperkenankan mengakses harta warisan di keluarganya demi menopang pendidikan saudara laki-lakinya di kota.

Masyarakat Pakpak yang berlatarbelakang kekerabatan patrilineal di desa ini sangat setia pada nilai-nilai tradisional dan mereka mensakralkan nilai adatnya. Pengaruh kekuasaan patriarki terlihat di berbagai elemen struktur sosial yang sangat dekat yaitu lembaga keluarga. Bahkan kekuasaan patriarki tertanam dalam lembaga lainnya yaitu lembaga hukum, adat, politik bahkan agama (Munthe, 2007, 2017; Bangun, 2013; Tinendung, 2012).

Hasil kegiatan pengabdian dengan menggunakan metode FGD tentang topik-topik gender, relasi gender serta ketimpangan gender dalam rangka pemberdayaan gender tokoh adat di desa ini pada intinya memperlihatkan masih rendahnya kesadaran gender para tokoh adat ini. Rendahnya kesadaran gender tokoh adat terutama dalam hal menyikapi kedudukan dan ketimpangan posisi sosal perempuan dalam masyarakat adat disebabkan tingkat pendidikan yang relatif rendah. Kebanyakan tokoh adat adalah berusia usia di atas 60 tahun dengan wwit http://mahesainstitute.web.id/ojs2/index.php/jehss 
latarbelakang pendidikan yang tidak tamat SD bahkan ada yang tidak lancar menulis dan membaca. Selain itu mereka juga cenderung sulit menerima informasi dan pengetahuan serta inovasi tentang keterlibatan perempuan dalam pembangunan.

Kondisi tingkat pendidikan dan pengetahuan yang minim dari para tokoh adat menimbulkan ketertinggalan untuk mengadopsi nilai-nilai pembangunan terutama dalam hal kesetaraan gender. Tidak hanya pada tokoh adat saja yang berpendidikan rendah sebaliknya peserta kelompok perempuan juga cenderung berpendidikan rendah yaitu rata-rata tamat SD dengan kategori usia antara 30 sampai 60 tahun.

Menyikapi rendahnya pendidikan serta tingkat pengetahuan para tokoh adat dan kelompok perempuan telah mendorong kegiatan pengabdian ini tidak hanya berhenti atau cukup dalam kegiatan FGD saja. Demi meningkatkan kesadaran gender para tokoh adat maupun perempuan di desa ini ditampilkan pula pemutaran film tentang tema-tema pembangunan yang melibatkan partisipasi perempuan di berbagai masyarakat di luar suku Pakpak. Tanpaknya mereka cukup antusias dan mulai mengerti mengapa program pembangunan di desa harus melibatkan seluruh partisipasi laki-laki dan perempuan. Sebagi penutup FGD dalam kegiatan pengabdian ini ditampilkan pula narasumber tokoh perempuan Pakpak yang sudah berhasil merintis karier di panggung politik nasional. Tujuannya adalah sharing pengalaman dalam rangka memotivsasi perempuan desa atau lokal untuk mau mengubah pemikiran dan percaya diri bahwa mereka memilki potensi memajukan masyarakat desanya. Di sisi lain para tokoh adat juga memiliki kesadaran gender untuk berpihak dan mendorong perempuan berperan dalam kegiatan pembanguinan desa. Para tokoh adat memiliki keberpihakan pada perempuan yaitu mendorong perempuan berani bersuara dan mengemukakan kepentingannya dalam programprogram pembangunan di pemerintahan adatnya. Hal ini mengingat tokoh adat di desa ini merupakan pemangku kepentingan yang mempunyai kekuasaan dalam mengatur kehidupan masyarakat desa.

\section{SIMPULAN}

Pemberdayaan gender yang dilakukan pada tokoh adat atau dewan adat di dalam masyarakat adat Pakpak desa Pegagan Julu VIII berangkat dari realitas yang memperlihatkan ketimpangan peran dan partisipasi perempuan dalam segenap aspek pembangunan. Realitas tersebut memperlihatkan dampak berupa fenomena beban ganda dan pemiskinan yang membelenggu perempuan karena secara kultural dan struktural adat mereka tersubordinasi bahkan termarginalkan dalam segala proses pembangunan di tengah masyarakatnya. Salah satu langkah untuk melakukan perubahan posisi sosial perempuan dapat dicermati dari posisi strtategis tokoh adat. Para tokoh adat merupakan stakeholder yang memiliki posisi strategis dan berpengaruh besar menaikkan posisi tawar perempuan dalam pembangunan di dalam komunitas masyarakat adat yang dipimpinnya. Mengingat posisi tokoh adat yang strategsi sebagai agen perubahan sosial di masyarakatnya maka kegiatan pengabdian yang berbasis pada pemberdayaan gender dilakukan pada mereka.

Metode FGD yang dilaksanakan selama kegiatan pengabdian memperlihatkan hasil yaitu pemahaman awal para tokoh adat tentang apa itu gender, kesetaraan gender dan ketimpangan gender pada intinya belum ada. Mereka menggunakan norma atau nilai-nilai adat sebagai pedoman untuk mengatur peran dan kedudukan laki-laki dan perempuan di dalam masyarakat adatnya. Dalam realitasnya adat samasekali tidak berpihak dan pro pada kedudukan sosial perempuan sebab adat cenderung menempatkan perempuan sebagai pihak yang tersubordinasi. Berpijak pada realitas gender yang sedemikian maka penyajian dan pendiskusian tentang topik ketimpangan gender serta kesetaraan gender semakin intens didiskusikan kepada para tokoh adat dan juga kelompok perempuan. Tujuan dari FGD ini demi menumbuhkan pemahaman yang tepat dan benar tentang realitas gender yang tidak menguntungkan pada kelompok tertentu yaitu perempuan. Di samping mendidikusikan topik-topik gender maka dalam kegiatan FGD, fasilitator juga memutar film bertemakan perempuan dalam pembangunan dari berbagai masyarakat dan negara. Hasil FGD dibarerngi dengan pemutaran film bertemakan pembangunan tampaknya menumbuhkan adanya kesadaran para tokoh adat dan juga kelompok perempuan untuk mau berperan dan terlibat mengambil bagian dalam kegiatan pembangunan desa. 


\section{DAFTAR PUSTAKA}

Bangun, S. (2009). Ketertinggalan Perempuan Batak Pakpak dalam Memperoleh Pendidikan Formal, http//isjd.pdii.lipi.go.id/index.php/Search.html?act =tampil\&id=74113\&idc=45

Berutu, L. dan Padang, N. (1998). Tradisi dan Perubahan pada Konteks Masyarakat Pakpak. Medan: Penerbit Monora.

Fakih, M. (2008). Analisis Gender dan Transformasi Sosial. Yogyakarta: Pustaka Pelajar.

Ginting, S. Achmad, N. \& Daulay, H. (2015). Ketimpangan Gender Dalam Relasi Kerja di Sektor Pertanian Dan Rumah Tangga. Departemen Sosiologi FISP, Universitas Sumatera Utara \& GIZ.

Elpina. (2016). Kedudukan Perempuan dalam Hukum Waris Adat Batak Toba. Biro Sistem Informasi Data dan Hubungan Masyarakat Universitas Simalungun. (www.usi.ac.id/karya ilmiah dosen/upload: sistem informasi data dan hubungan masyarakat@2016 di akses pada tanggal 11/07/2018/21.23)

Munthe, H.M. (2017), Phenomenon of Women Marginalization in Poor Family in Pakpak Community: "A Case Studi in PegaganJulu Village, Sumbul Subdistrict, Dairi Regency, North Sumatera", Journal of Arts \& Humanities, Volume 06, Issues 06, 38-51.

Murniati, P.N. (2004). Getar Gender (Perempuan Indonesia dalam Prespektif Agama dan Keluarga). Mangelang: Yayasan Adikarya IKAPI.

Nurmila, N. (2015). Pengaruh Budaya Patriark Terhadap Pemahaman Agama. Bandung: Universitas Islam Negeri Susan Gunung Djati.

Pardede, E. (2010). Menelusuri Bentuk-bentuk Kekerasan Perempuan di Masyarakat Adat, Sidikalang: Penerbit Pesada. Pesada.

Revida, E. (2006). Sistem Kekerabatan Masyarakat Suku Batak Toba Sumetera Utara. Departemen Ilmu Administrasi Negara FISIP dan Program Pascasarjana USU. Jurnal Pemberdayaan Komunitas. 2006, Vol. 5, No.2, Hal 213-218.

Rokhimah. (2014). Patriarkhisme \&Ketidakadilan Gender. Jawa Timur: Muwazah, Vol. 6, No. 1 Juli 2014.

Saadawi, E.N. (2001). Perempuan dalam Budaya Patriarki. Yogyakarta: Pustaka Pelajar (Anggota IKAPI). 